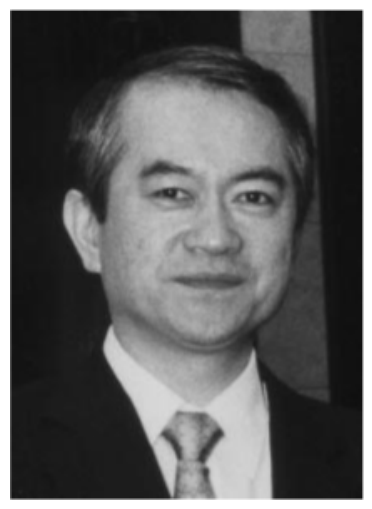

Dr. Hisamaru Hirai 1952-2003

\title{
A Tribute to the Memory of Hisamaru Hirai, MD, PhD Professor of the Department of Hematology and Oncology Graduate School of Medicine, The University of Tokyo
}

Int J Hematol. 2003;78:279.

(C)2003 The Japanese Society of Hematology

Professor Hisamaru Hirai, Professor of the Department of Hematology and Oncology, Graduate School of Medicine, the University of Tokyo, passed away on August 23, 2003, at the age of 51. The cause of his sudden death was widespread myocardial infarction, which was confirmed by an autopsy.

Dr. Hirai graduated from the Faculty of Medicine, the University of Tokyo, in 1979. After finishing his 2-year postgraduate medical education in 1982 at Tokyo University Hospital and Jichi Medical School Hospital, he selected as his career specialization in hematology at the 3rd Department of Medicine, Faculty of Medicine, the University of Tokyo.

When I became professor of the 3rd Department of Medicine in 1982 at the University of Tokyo, I noticed that Dr. Hirai was conducting research on the alteration of oncogenes in tumors at the Department of Nutrition, the University of Tokyo, as a research fellow. Realizing that Dr. Hirai's research should be one of the main areas of future hematology research, I decided to set up a new laboratory in the 3rd Department of Medicine and appoint him as the head of the new laboratory. Dr. Hirai was promoted to assistant professor of the 3rd Department of Internal Medicine, the University of Tokyo. He responded to our expectation with several outstanding studies on the oncogene mutations in leukemic cells as well as in hematopoietic cells in patients with myelodysplastic syndrome. Those studies were published in leading international journals including Nature and Science.

Thereafter Dr. Hirai was a leader in the field of molecular hematology in our country and worldwide as well. His name and work on the alteration of oncogenes in various hematological disorders has been recognized and highly evaluated among world scientists. He was the leader of a large hematology group in the Graduate School of Medicine at the University of Tokyo for many years. Dr. Hirai was promoted to professor in May this year, and everybody believed and expected that he would be leading the science of hematology and oncology globally. He had been devoting himself to the care of hematology patients and developed a strong bone marrow transplantation team at Tokyo University Hospital. He was an excellent teacher, too. He was loved and respected by every medical student without exception.

Dr. Hirai's sudden death is a real loss for the progress of medical, biological, and molecular sciences, and for clinical hematology and oncology not only in Japan but also worldwide. He used to be my student. When Professor Kiku Nakao, Honorary President of Jichi Medical School and Honorary Professor of the University of Tokyo, passed away in June, 2001, my grief was for the loss of my father in hematology. This time, with the demise of Professor Hirai, I acutely feel I have lost my most precious son in hematology.

Professor Hirai is survived by his wife and two daughters.

Fumimaro Takaku, MD, PhD

President of Jichi Medical School Honorary Professor of the University of Tokyo 